\title{
Patient needs from general practice following a traumatic injury: a qualitative study using narrative interviews with British service personnel
}

\author{
Thomas R Bailey
}

\section{Correspondence to}

Sqn Ldr Tom Bailey, SMC, RAF

Shawbury, Shrewsbury,

Shropshire SY4 4DZ, UK;

mda00trb@hotmail.com

Received 25 February 2013

Revised 12 June 2013

Accepted 27 June 2013

Published Online First

8 August 2013
To cite: Bailey TR. J R Army Med Corps 2014;160: $46-51$.

\begin{abstract}
Objectives To explore the first period of sick leave in military patients following a traumatic battle injury, and the role of primary care. To identify if and where patients perceived difficulties.

Method Participants were recruited from The Defence Medical Rehabilitation Centre (DMRC) Headley Court on their second admission. Purposive sampling was used to access a range of different injuries and experiences. Nine patients were interviewed at DMRC where they were asked to recount their stories throughout rehabilitation. Thematic and structural analysis of the narrative accounts was applied.
\end{abstract}

Results The majority of problems encountered by the participants occurred during their initial period of sick leave between Royal Centre for Defence Medicine (RCDM), Queen Elizabeth Hospital, Birmingham, and DMRC. Participants often had difficulty identifying who to contact if they had a problem on sick leave, with many ringing secondary care directly. Time spent travelling to medical reviews was identified as affecting the quality of leave.

Conclusions There is a need for greater patient understanding regarding whom to contact should they develop problems while on sick leave. A patient passport containing all discharge documentation and simplified contact details may help reduce patient confusion regarding whom to contact. GPs require greater awareness and understanding of the complexity of these patients' injuries and the need for early secondary care review to prevent delayed or inappropriate admissions. Most problems that patients face will occur on their first period of sick leave. Reducing the time spent on sick leave before admission to DMRC would limit the likelihood of problems occurring at this high-risk time.

\section{INTRODUCTION}

The UK has committed forces to fight alongside NATO allies in Afghanistan since 2001. The number of fatalities and injuries sustained has increased significantly since January 2006, when an additional 3700 troops were deployed as part of the International Security Assistance Force (ISAF) stabilisation force. To date, 401 British personnel have been killed by hostile action since the start of operations in $2001^{1}$; for every service person killed in action approximately five more are injured. ${ }^{2}$ Improvements in battlefield care and equipment have been credited for reducing the mortality rates of those injured in combat to between $10 \%$ and $16 \% .^{1-4}$ The combination of an increase in casualties and improved survival rates has resulted in an increased number of patients requiring rehabilitation.

\section{Key messages}

The experience of patients moving from Royal Centre for Defence Medicine (RCDM) to Defence Medical Rehabilitation Centre (DMRC) could be improved thus.

- Reduce the period of sick leave between discharge from RCDM and admission to DMRC.

- Improve patient discharge information through improvements to the patient passport:

- Combine all discharge information into the patient passport and make it easily identifiable.

- Reduce contact information to the local medical centre and an emergency single point of contact to reduce patient confusion.

- Improve collaboration with NHS GPs through the inclusion of a letter requesting help if necessary, and an area to document clinical findings if DMICP is not available.

- Additional training for GPs in the management of complex trauma patients in primary care and when to contact secondary care.

Patients are admitted to the Defence Medical Rehabilitation Centre (DMRC) for treatment blocks of between 4 and 6 weeks. This model of short, high-intensity rehabilitation has proved very successful and has recently been adopted by the Canadian military. ${ }^{2}$ Depending on the severity of their injuries some patients spend time on sick leave before attending DMRC, and most patients will have periods of sick leave between rehabilitation admissions. Sick leave is usually spent either at home or close to family where their care is managed by their local GP. This research explores the initial period of GP involvement in the rehabilitation process as there is no published literature exploring this.

The lack of literature could be explained by different healthcare systems; primary care systems in the USA are not as well developed as in many parts of Europe. US soldiers are cared for in rehabilitation centres called 'Warrior Transition Units', or discharged from the military to be cared for as veterans. ${ }^{5}$ The long-term follow-up of US military veterans has been documented in cohort studies following the Vietnam War. ${ }^{6} 7$ Dougherty demonstrated that soldiers who sustained multiple injuries suffer significantly more disability, ${ }^{6}$ and are likely to have the greatest long-term need from general practice. 
High-quality early rehabilitation can have a significant impact on improving the outcome for injured servicemen ${ }^{8}$ with rehabilitation often advancing during periods of conflict. ${ }^{9}$ Recent advances in rehabilitation and improvements in prostheses have been shown to improve quality of life leading to a greater number of soldiers returning to duty than in previous conflicts. ${ }^{10}$ A lack of rehabilitation or poor quality rehabilitation is likely to lead to chronic problems, ${ }^{11}$ many of which could present to general practice in the future. While patients are in hospital at the Royal Centre for Defence Medicine (RCDM) or at DMRC they are well supported and monitored for posttraumatic stress disorder (PTSD). Acutely, patients may have difficulty adjusting to their injuries ${ }^{12}$ and may be reluctant to seek help. ${ }^{13}$ PTSD in patients injured or exposed to conflict commonly develops after several months ${ }^{14}$; therefore, GPs must be aware of this when patients are returning to their care after and during rehabilitation. ${ }^{15}$ Other psychological problems may not manifest themselves until years later; this has been identified in recent guidance for GPs on treating veterans. ${ }^{16}$

The literature contains no studies relating to GP involvement in the care of injured UK service personnel during or following rehabilitation. This study aims to explore the transition between rehabilitation and primary care in the military. It describes patient experiences of rehabilitation and subsequent interaction with primary care, and identify areas where patients faced difficulties through analysis of narrative accounts.

\section{METHODS}

Qualitative research methods were used to fully understand if, and in what ways, patients perceived there to be problems in the care that they receive from general practice, and to gain an appreciation of the patients' journey through the rehabilitation process. An 'emotionalist' approach, as described by Silverman, ${ }^{17}$ was used to permit a more authentic account of the patients' subjective experiences. It allowed issues pertinent to the patient to be highlighted through their own account. Purposive sampling was used within the bounds of the limited patient population, to ensure there was a range of injuries, mechanism of injuries and experiences. It was anticipated that the interview process would generate a large volume of data. This, in conjunction with the time-consuming nature of the data gathering and the potentially limited pool of patients, restricted the size of the study to between eight and twelve patients. This number was appropriate because of the time constraints placed on the project and the in-depth nature of the analysis.

Patients were recruited from the complex trauma unit at DMRC Headley Court in August 2011 following ethical approval; interviews took place between 4 October and 22 November 2011. To be included in the study, patients had to meet four inclusion criteria (Box 1). Participants were excluded from the study if they were so cognitively impaired as to make discussion of their care impossible, for example, through brain injury. Patients had to be on their second admission to ensure that they had spent at least one period of time on sick leave where they would have been under the care of a GP. This ensured that their memories of their initial experiences were still clear, hopefully improving the quality of their recollections.

Eleven patients were recruited into the study; two participants withdrew, so interviews were conducted with the remaining nine. All the interviews took place in private side rooms on the complex trauma wards at DMRC after written consent was taken from each participant.

Each participant was asked to describe their experiences throughout the rehabilitation process from the point of injury

\section{Box 1 Study inclusion criteria}

- Participants had sustained a traumatic injury during combat operations in Iraq or Afghanistan.

- They had been admitted to the complex trauma ward at Defence Medical Rehabilitation Centre and were in their second admission.

- Participants had spent at least one period of time at home or back at their unit where they had been under the care their GP.

- Participants had to be fluent English speakers.

through to their most recent admission at DMRC during a narrative interview. Open-ended interviews were used to limit researcher influence on the participants and to allow participants to raise issues that might not have been covered by a prescriptive interview schedule. ${ }^{18}$ Participants were asked to recount their entire experiences throughout the rehabilitation process, but were not told which part of their experience was being investigated. Participants who did not discuss their experiences on sick leave or contact with primary care were directed to these areas once they had finished recounting their story. When participants made brief reference to their experiences on sick leave or interaction with primary care they were encouraged to elaborate. To ensure that all concerns were covered, prior to ending the interview, participants were asked if there was 'anything else they would like to add' and if 'there were any areas of their care that could be improved for others in the future?'

Thematic and structural analysis was performed on the patient narratives to triangulate the data, increasing validity. ${ }^{19} \quad 20-22$ A framework approach to coding was used, with the coding being an iterative process. 'Descriptive codes' were applied to single words or small sections of text during the first cycle of coding. ${ }^{23}$ A second cycle of focused thematic coding was then applied. Computer-assisted qualitative data analysis software (NVivo9), aided the organisation of the coding process. Structural analysis was used to break the narratives down into a timeline of events and to provide triangulation, increasing the validity of the data. Individual codes were grouped to produce a list of themes. Due to the richness of the data generated by the narratives, certain themes were removed from the analysis as they were not related to the research question. Participants are identified by the letters A-I in the results below.

\section{RESULTS}

Nine servicemen were interviewed about their experiences through rehabilitation. They ranged in rank from Private or Marine to Major, and in age from 22 years to 34 years old. All were recruited from the Army or Marines due to the patient population at the time of recruitment. Participants had sustained a range of injuries including bilateral lower limb amputations, upper limb injury, nerve injury, unilateral above-knee amputations, lung injury, fractures and fragmentation wounds. Injuries were caused by improvised explosive devices (IED) and gunshot wounds. The participants included both regular and reservists; British and Commonwealth nationals.

Thematic and structural coding and analysis of the interviews revealed eight key themes which were divided into those relating directly to general practice and those relating to sick leave (Box 2). This paper discusses those themes relating to general practice. 
Box 2 Themes developed following thematic coding and structural analysis

\section{GP-related themes}

- The majority of problems encountered on sick leave occurred during the first period of leave

- Primary care provision should be local to reduce time spent travelling to medical appointments while on leave

- Difficulties identifying a primary point of contact for medical problems on sick leave means patients contact secondary care directly

- GPs require a greater understanding of the complexities of complex trauma and when secondary care referral is required

Sick leave-related themes

- Sick leave following Defence Medical Rehabilitation Centre admission provides the opportunity for recovery and development

- Sick leave provides time for adjustment, recovery, reflection and progression

- Difficulties obtaining and taking medications

- Military welfare and administrative systems are effective at providing support for injured servicemen

\section{Box 3 The majority of problems encountered on sick} leave occurred during the first period of leave

\section{Accident on sick leave}

"I slipped on a bit of water and I fell on my stump...that put me basically in bed for like three or four days." [I]

Readmission to hospital

"Ultimately when I came here (DMRC) and the consultant saw it (fracture blister), straight away he was like "I'm not happy with that, you're going back to Birmingham tonight" sort of thing." $[\mathrm{G}]$

Not ready for sick leave

"I had that two weeks sick leave so in the first week I felt absolutely awful. Didn't sleep, couldn't sleep. So yeah, quite looked forward to getting to Headley because then, it's kind of, there's more care... yeah I probably wasn't actually ready to go home if I'm honest." [B]

"It was not that great I mean I don't think leave's the best thing after Birmingham because you were just so restricted... so yeah I personally think you should come straight here (DMRC) and maybe have a long weekend... but two weeks off is just dramas." [I]

\section{Initial difficulties on sick leave}

"There's one door in my house... which has a door knob not a handle... I remember just like flashing at the door because I couldn't get in or out, just getting in and out the house was just stupid." [C]

\section{Overexertion on sick leave}

"That second week I then overexerted a bit although it wasn't doing much, just trying to help out around the house..." [B]

\section{Wheelchair access}

"Although in the entrance and exit of this place has steps or had a step, they only had one ramp. So if you wanted to go from the room to, you know... you had to take the ramp with you which was this big, felt like it was $f^{* *}$ king cast iron." [A]
The majority of problems encountered on sick leave occurred during the first period of leave before admission to DMRC

Structural analysis using a timeline of events from each narrative showed that only two of the nine participants had been admitted directly from hospital to DMRC. The remaining seven participants had spent time either at home, or in alternative accommodation on sick leave prior to their first admission. Six of the participants who spent time on sick leave described difficulties during this time (Boxes 3 and 4). They described a range of problems; mobility difficulties, such as wheelchair access, accidents requiring hospital treatment and readmission to hospital with wound infections. Several participants described overexerting themselves while on leave (Box 3). Participants were more functional during sick leave following admission to DMRC, being able to consolidate the skills they had acquired during the admission. This resulted in more productive and enjoyable sick leave, with most of the participants able to go home and one even going on holiday (Box 4).

Primary care provision should be local to reduce time spent travelling to medical appointments while on sick leave Travelling for regular reviews with a military medical officer caused a significant disturbance to sick leave for four participants, especially those who were reservists (Box 5). One

Box 4 Sick leave following Defence Medical Rehabilitation Centre admission provides the opportunity for recovery and development

\section{Enjoyable leave}

"They sent me home for a month...it was good leave you know I mean. The first week my missus took off with me... And then my parents came over...this was the first time they had seen me up and about." [A]

"I went to Bermuda and I think that was just what the doctor ordered, like it was the first break not just for me but for my family and for my missus most important like..." [C]

\section{Sick leave to recover}

"I had three weeks at home which was brilliant because I didn't see any one, I was left to my own devices which done me the world of good...it was a nice three weeks at home and I come here now and I'm raring to go." [F]

"I wanted as much time to myself as I could possibly get because I hadn't been home in eight months ...I just kind of sat in the house and basically enjoyed sitting in the house." $[\mathrm{H}]$

\section{Progression}

"The third day into this leave (because I had three and a half weeks off) I just thought, no I'm just going to leave them (crutches) in my car... I walked basically just by leaving my crutches in one place and not using them. I walked about three and a half; four K's towards the end of my leave so I think that, that's helped me progress really quickly." [I]

\section{Normality/family life}

"Time is a good healer so I was able to help out more at home a lot more. My wife had quite a bit of consultancy work on so I would look after the kids..." [B]

"I'd been away for such a long time and coming back it was quite hard, well sort of fitting back into normal family life, just trying to get a bit of normality for three weeks." [F] 
Box 5 Primary care provision should be local to reduce time spent travelling to medical appointments while on sick leave

Travel
"Because you had to go in every day you couldn't say if you
wanted to go out for the day, sort of plan to go somewhere... I
just didn't feel that I had rested properly." [F]
"I live in Liverpool so my options are only either Chester or
Preston I think, it's roughly the same I think Chester is slightly
closer...It's about forty minutes from the house... (Local NHS
GP) It's about five minutes from me, ten minutes walking on my
crutches." [G]
"Basically I had to re-arrange it (physio)...I had to re-arrange it
to Faslane because Faslane was closer and quicker to get to....I
done because I wanted as much time to myself as I could
possibly get." [H]
"HMS Nelson is a forty-five minute drive around Gosport so
actually it was a bit of pain say for my wife, two young children
(actually had been a bit of a nightmare for her) so, at
Birmingham they said 'Well just register with your local, as
temporary patient with your local surgery' which is just half a
mile down the road." [B]

participant was able to negotiate a review with a local NHS doctor to reduce the travel time for dressings, however, other participants were not aware of this option. The frequency of travel for wound review was described as 'stressful' by one participant, and this resulted in them starting their rehabilitation at Headley Court tired and in the 'wrong mind frame' (Box 5).

\section{Difficulties identifying a primary point of contact for} medical problems on sick leave means patients contact secondary care directly

On discharge from RCDM, patients are issued with a 'patient passport' which contains all the contact numbers and details they require should they encounter a problem while on sick leave (Box 6). Patients have to sign that they have been issued a passport and had it explained to them. Only three participants made any reference to a "patient passport" [G] or "envelope of documents." [D]. "I had a document that they gave me in Birmingham that basically was a summary of my injuries and what medication I was on and what had happened... only a two pager." [B]

However, five participants were aware that they should contact their medical centre in the first instance should they have had a problem (Box 6). "I didn't go to my Med Centre on camp at all, I didn't feel the need to, but I knew if I needed, If I wanted to I knew they were always there.” [E] Unfortunately, those who were not aware of who to contact often bypassed primary care and rang or travelled to secondary care centres directly (Box 5).

General practitioners require a greater understanding of the complexities of complex trauma patients and when secondary care referral is required

Participants who required simple wound dressings or reviews appeared to have little problem with GP or primary care reviews. In participants who had wounds that were more complex, or developed complications, the reviewing GPs did
Box 6 Difficulties identifying a primary point of contact for medical problems on sick leave means patients contact secondary care directly

\section{Uncertain who to call}

"But there was a sort of moment in those two weeks when they sent me home I wasn't sure who was looking after me in a way, I knew it was going to soon be Headley but I didn't kind of know, although to be fair everyone says 'if you've got a problem, phone me' you know, so I could have phoned anyone but I was kind of like 'who should I go to?'" [C]

\section{Direct patient contact with secondary care}

" $\left(I^{\prime} m\right)$ not saying our local units don't necessarily have the expertise but they don't see you as regularly, when you've done various stints like myself it's much better to go back and see and literally walk in and see your consultant who operated on you and he will see you straight away; so although it's about an hour and a half, two hours trip we would now rather spend that time going back to Birmingham." [G]

"I would have phoned a hand surgeon straight away and the hand team down at QE... they gave me their mobile numbers and told me to 'get in touch if you have any problems' and with my arm I would have gone straight back to the doctors." [C] "I spent too much time walking on this (prosthesis)...it (stump) had blisters all over it, and blood coming out of it, and I was like 'Right I need to call someone and get some help' So I called down here, (DMRC) talked to $F$ who is an RAF sergeant... She said 'if you can get down here, come down here.'" $[A]$

not always understand, or have clear instructions regarding when to refer back to secondary care (Box 7). In one case this resulted in delayed referral with the participant losing confidence in the GP. Conversely in another case the participant felt that the GP was overly cautious when reviewing and referring back to secondary care. This caused friction between the

\section{Box 7 General Practitioners require a greater} understanding of the complexities of complex trauma patients and when secondary care referral is required

\section{GP did not understand the significance}

"Whereas he's just a normal GP isn't he... he doesn't come across injuries like this every day, so he doesn't really have a full understanding. So I think that's why he wanted to get me up to (QE)." [F]

"Obviously they (GP) had taken swabs etc, you know I was on antibiotics and they were treating it, but I don't think necessarily they may be understood how serious it was." [G] Lack of patient confidence in GP

"I definitely recommend any one if they are worried about injuries etc or wounds to go straight back, always use Queen Elizabeth, not saying our local units don't necessarily have the expertise but they don't see you as regularly when you've done various stints like myself it's much better to go back." [G] "He was trying to send me back to the Queen Elizabeth which I was not very happy about so I basically refused and said I'm not going back there, there's nothing, it's only a bit of swelling on my leg that just needs a bit of rest." [F] 
participant and GP with the participant refusing admission back to hospital, finding the regular GP reviews disruptive and stressful.

\section{DISCUSSION}

This research set out to identify patient needs from general practice following a traumatic injury. However, in doing so, it has highlighted some important issues relating to GP provision and also the discharge process and sick leave. The majority (6/9) of the participants interviewed had experiences of sick leave before admission to DMRC. The structural analysis supported by themes developed through thematic analysis has demonstrated that the majority of problems that patients face occur during this period of time. Sick leave taken after DMRC admission tended to be far more successful since participants had been stabilised on their medications, wounds had healed so did not require dressings, and the rehabilitation had improved the participants strength and functionality. Unfortunately, many participants appeared ill prepared for sick leave before admission to DMRC resulting in minor accidents, overexertion and mobility difficulties.

During the time between discharge from RCDM and admission to DMRC many participants had wounds (some of which were complex) that required regular medical reviews in primary care. Time spent travelling to these reviews often resulted in significant disruption to the participant, with GPs sometimes misunderstanding the significance of signs. This resulted in one participant's readmission to hospital being delayed and their subsequent loss of trust in primary care. Better communication between secondary and primary care, and additional training for GPs to improve their understanding in the management of these complex patients may have prevented this. Several participants contacted secondary care or DMRC directly for advice and were unsure who to contact if they encountered a problem while on sick leave under the care of general practice. Changes to the patient passport document could improve patient knowledge and understanding about who to contact regarding their care while on sick leave and under the care of primary care. Currently, patients are provided with important information on the patient passport; but only three participants were aware of this. The patient passport is a two-sided A4 document, and patients have to sign to say that they have received it; however, it could easily be lost in the discharge process. Improving the identity of this document so that it is a booklet or folder, similar to those used by pregnant women, may reduce the chances of it getting lost. Highlighting the contact details of the local medical centre on the front of this may help patients to engage with primary care when needed. Including other important information, such as discharge summaries in this, would aid communication between secondary care and the GP, especially if the GP is in the NHS and does not have access to the Defence Medical Information Capability Programme.

Sick leave has been shown to be important as it provides the patient with time to recover, and it can also help the families of those that have been injured. However, if sick leave is given at the wrong time it can create problems, increasing the stress for the family resulting in many of the difficulties previously discussed. Considering that most of the problems encountered by the participants on sick leave occurred between RCDM and DMRC, and that sick leave following an admission at DMRC was usually successful, reducing or removing the sick leave before admission to DMRC may reduce the scope for problems on leave. It may help to ensure patients' first experience of sick leave is positive, enabling them to return ready for their next admission. To do this would require greater discharge planning between RCDM and DMRC.

\section{Limitations of the study}

The sample of patients used in this study was representative of the patients who were undergoing rehabilitation at DMRC at the time the study was conducted, so it may not be representative of all patients who have experienced rehabilitation through DMRC in recent years. The sample size was deliberately small given the nature of the project and the in-depth analysis. However, areas that have been highlighted in this research could be investigated further to include a greater proportion of the patient population.

\section{Future research}

This research focuses on patients' perceived needs from general practice; an area for future research would be to ask GPs about the difficulties they face when treating these complex patients, and if there are areas in which additional training is required. It would be useful to identify if information is being communicated effectively from secondary care through to GPs. Such studies could then inform changes to the patient passport and discharge process.

\section{Postscript}

In January 2012, the discharge process at RCDM was changed so that patient sick leave was limited to a maximum of a weekend or night in a hotel before admission to Headley Court. This decision was taken independently of this research, but this research would support that decision. The patient passport has also been recognised to be deficient and not distinct enough, despite its importance being stressed to patients prior to discharge from RCDM. Work is now in progress to print the passport on card and in colour, and a patient folder is being designed to keep all patient documentation together, to reduce the chances of documents going missing, or patients not understanding who to call for assistance should they need to while on leave.

\section{Collaborators Nicola Gale, Robin Simpson.}

Contributors This paper was designed, data gathered and written by the author. Guidance was provided by Dr Nicola Gale on the technical qualitative research. Military guidance was provided by Col Robin Simpson. This paper is based on data gathered as part of an MSc at Birmingham University.

\section{Competing interests None.}

\section{Patient consent Obtained.}

Ethics approval This study was approved by the MoD Research Ethics Committee and The RAF Scientific Committee.

Provenance and peer review Not commissioned; externally peer reviewed.

Data sharing statement A more detailed MSc dissertation write-up for this research is available upon request to the primary author. Full interview transcripts have not been published to try and maintain patient confidentiality since patients could potentially be identified through their unique stories. Sections of transcripts have been used throughout the paper to illustrate themes elicited. A complete copy of the coding process is available upon request, but has not been published.

\section{REFERENCES}

1 Ministry of Defence. UK Forces: Operations in Afghanistan; British fatalities. $30 \mathrm{Apr}$ 2013. https://www.gov.uk/uk-forces-operations-in-afghanistan\#british-fatalities (last accessed 27 May 2013).

2 Besemann M. Physical rehabilitation following polytrauma. The Canadian Forces Physical Rehabilitation Program 2008-2011. Can J Surg 2011;54:s135-41.

3 Gawande A. Casualties of war- Military care for the wounded from Iraq and Afghanistan. N Engl J Med 2004;352:219-22.

4 Pomeranz JL, Shaw LR, Nami S, et al. Polytrauma and life care planning: Managing the complex interaction of multiple injuries. Work 2008:31:319-26. 
5 Dominguez MA. The comprehensive care plan: building the strength to do well tomorrow. US Army Med Dep J 2008:8-16.

6 Dougherty PJ. Transtibial Amputees from the Vietnam War: twenty-eight-year follow-up. J Bone Joint Surg Am 2001;83-A:383-9.

7 Dougherty PJ. Long-term follow-up of unilateral transfemoral amputees from the Vietnam War. J Trauma 2003;54:718-22.

8 Pirowska A, Wloch T, Nowobilski R. Immediate prosthesis fitting and comprehensive rehabilitation following lower limb amputation-the most important components of physiotherapy. Med Rehabil 2006;10:9-26.

9 Eldar $\mathrm{R}$, Jelic M. The association of rehabilitation and war. Disabil Rehabil 2003;25:1019-23.

10 Stinner DJ, Burns TC, Kirk K, et al. Return to duty rate of Amputee Soldiers in the current conflicts in Afghanistan and Iraq. J Trauma 2010;68:1476-9.

11 Khani H, Azadmarzabadi E, Karimi Nasab MH, et al. Clinical orthopaedic and rehabilitation assessment of lower limb amputees verterans in Maandaran province. Mil Med-Journal 2011;12:229-34.

12 McFarland LV, Winkler SLH, Heinemann AW, et al. Unilateral upper-limb loss: satisfaction and prosthetic-device use in veterans and servicemembers from Vietnam and OIF/OEF conflicts. J Rehabil Res Dev 2010;47:299-316.

13 Hoge C, Castro CA, Messer SW, et al. Combat duty in Iraq and Afghanistan, Mental Health Problems and Barriers to Care. N Engl J Med 2004;351:13-22.
14 Grieger TA, Cozza SJ, Ursano SJ, et al. Posttraumatic stress disorder and depression in battle injured soldiers. Am J Psychol 2006;163:1777-83.

15 Quinlan JD, Gauron MR, Deschere BR, et al. Care of the returning veteran. Am Fam Physicians 2010;82:43-9.

16 Royal College of General Practitioners. Meeting the health care needs of veterans, 2010.

17 Silverman D. Credible qualitative research. In: Interpreting qualitative data: methods for analyzing talk, text and interaction. 3rd edn. London: Sage Publishing Ltd, 2006;124-5.

18 Denzin NK. The Research Act in Sociology: a theoretical introduction to sociological methods (cited Silverman 2006 pp 125). London: Butterworth, 1970.

19 Paley J, Lilford R. Qualitative methods: an alternative view. BMJ 2011:342:956-8.

20 Riessman CK. Thematic analysis. In: Narrative methods for the human sciences. Thousand Oaks, CA: Sage Publications Inc, 2008;53-76.

21 Riessman CK. Structural analysis. In: Narrative methods for the human sciences Thousand Oaks, CA: Sage Publications Inc, 2008;77-104.

22 Silverman D. Credible qualitative research. In: Interpreting qualitative data: methods for analyzing talk, text and interaction. 3rd edn. London: Sage Publishing Ltd, 2006;289-95.

23 Saldana J. First cycle coding methods. In: Seaman J, ed. The coding manual for qualitative researchers. London: Sage Publications Ltd, 2009;45-148. 